\title{
Polymethoxy flavones do not exert an inducing effect on the biosynthesis and secretion of insulin by pancreatic $\beta$-cells
}

\author{
HAO DONG* ${ }^{*}$ HONG-DONG CHEN* ${ }^{*}$ YI-JUN ZHAO and HONG-MIN LI \\ Department of Bioscience, Faculty of Life Sciences, Northwest University, Xi'an 710069, P.R. China
}

Received March 20, 2013; Accepted January 02, 2014

DOI: $10.3892 /$ br.2014.223

\begin{abstract}
Polymethoxylated flavones (PMFs), which are compounds characteristic of citrus plants, possess a wide range of biological properties, particularly affecting glucose and lipid metabolism. However, the mechanism underlying the antidiabetic activity of PMFs has not been fully elucidated. In this study, we aimed to investigate the potential effect of PMFs on the biosynthesis and secretion of insulin, which are crucial in diabetes. We investigated whether PMFs are able to induce insulin secretion by pancreatic $\beta$-cells and observed that different concentrations $(12.5,25,37.5$ and $50 \mu \mathrm{g} / \mathrm{ml})$ of PMFs exerted no effect on insulin synthesis and secretion in INS-1 cells, regardless of the glucose levels. To the best of our knowledge, this is the first study to demonstrate that the regulation of glucose and lipid metabolism by PMFs is not mediated by directly affecting insulin synthesis or secretion. Therefore, further studies are required to elucidate the role of PMFs in diabetes.
\end{abstract}

\section{Introduction}

Citrus plants are rich sources of health-promoting substances (1) and contain several different types of flavonoid constituents. Recently, these flavonoids have attracted considerable scientific interest due to their therapeutic properties. Some of these compounds, such as hesperidin, naringin and polymethoxylated flavones (PMFs), are characteristic of citrus plants, whereas others, such as rutin and quercetin, are commonly encountered in the plant kingdom (2). Among these compounds, PMFs are of particular interest, due to their extensive biological activities, including anticancer, anti-inflammatory, antioxidant, antimutagenic and antimicrobial activities (3-9). The composition of PMFs may differ significantly among different citrus species. The interest on the biological activities of PMFs is currently

Correspondence to: Professor Hong-Min Li, Department of Bioscience, Faculty of Life Science, Northwest University, 229 North Taibai Road, Xi'an 710069, P.R. China

E-mail: hongminli3484@gmail.com

${ }^{*}$ Contributed equally

Key words: polymethoxylated flavones, insulin secretion, PDX1 focused on the main components, nobiletin and tangeretin. Nobiletin was found to suppress the DNA-binding activity of NF- $\kappa \mathrm{B}$ and the production of ROS in lipopolysaccharideactivated RAW 264.7 cells (10), whereas it was also found to posses anticancer and antiproliferative properties $(11,12)$. In comparison, tangeretin inhibits interleukin-1- $\beta$-induced cyclooxygenase-2 expression (13) and it also inhibits the activity of cyclin-dependent kinases 2 and 4, subsequently inducing a cell cycle arrest in G1 (14). Given their biological properties, a rapid, large-scale procedure for separating PMFs may be of great value $(15,16)$. It was previously demonstrated that Citrus sunki Hort. ex Tanaka is a rich source of PMFs (17).

PMFs were shown to possess antiatherosclerotic activity, inhibiting the formation of atheroma in several steps during its pathogenesis (18). PMFs also play important roles in lipid metabolism. However, there is currently no evidence of a direct involvement of these compounds in diabetes. In this study, we investigated the potential role of PMFs in insulin secretion by rat pancreatic cells.

\section{Materials and methods}

Reagents. PMFs (the main component was nobiletin, with $98 \%$ purity) were extracted from Pericarpium CitriReticulatae in our laboratory. The ELISA kit for insulin detection was purchased from Gibco BRL (Gaithersburg, MD, USA). Fetal bovine serum (FBS) was purchased from HyClone Laboratories, Inc. (Logan, UT, USA). The reverse transcriptase-polymerase chain reaction (RT-PCR) kit and DNaseI (RNase-free) were purchased from Life Technologies (Gaithersburg, MD, USA). MTT, diethylpyrocarbonate, RPMI-1640 and TRIzol were purchased from Invitrogen (Carlsbad, CA, USA). HEPES, kanamycin and ampicillin were purchased from Amersham (Piscataway, NJ, USA). Trypsin and standard PMF samples were obtained from Sigma Chemical Co. (St. Louis, MO, USA). Pericarpium Citri Reticulatae were obtained from Zaolutang (Xian, China). High-performance liquid chromatography (HPLC) grade methanol and other chemicals (analytical grade) were obtained from Merck (Darmstadt, Germany).

Extraction and purification of PMFs. PMFs were extracted from dried Pericarpium Citri Reticulatae as previously described $(19,20)$. The measurement of nobiletin, the main component of PMFs, was performed on a Thermo Finnigan 
A

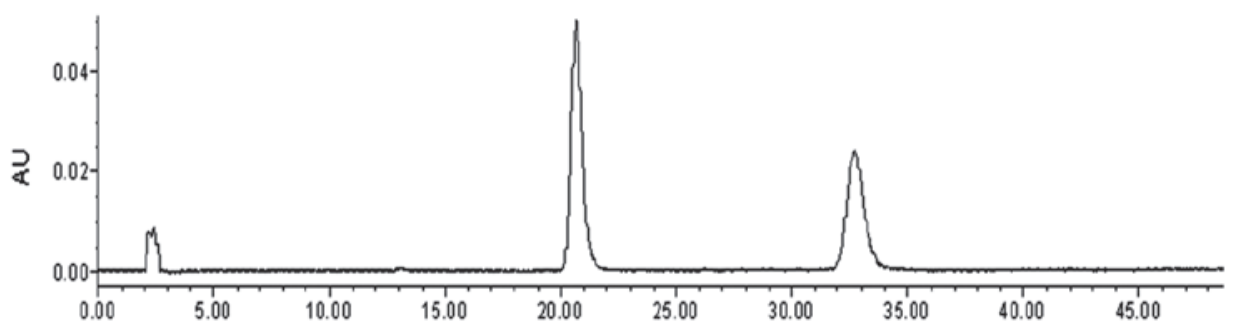

B

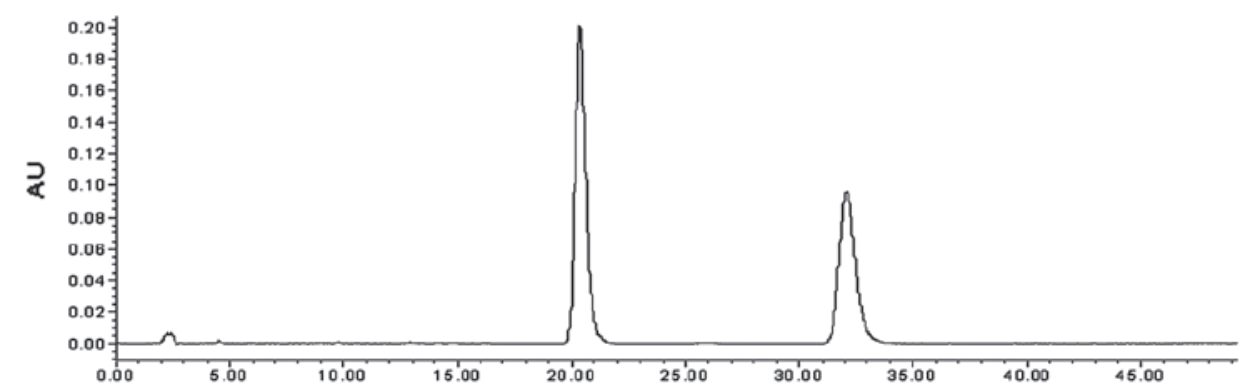

Figure 1. High-performance liquid chromatograms of polymethoxylated flavones (PMFs). (A) PMFs standards; (B) PMFs samples. AU, absorption units.

HLPC system (Thermo-Finnigan, San Jose, CA, USA) as previously described $(16,21)$.

Cell culture. The rat INS-1 pancreatic $\beta$-cell line was cultured in RPMI-1640 medium supplemented with 10\% FBS, $10 \mathrm{mmol} / 1 \mathrm{HEPES}, 11.1 \mathrm{mmol} / 1$ glucose, $50 \mu \mathrm{g} / \mathrm{ml}$ ampicillin, $50 \mu \mathrm{g} / \mathrm{ml} \mathrm{kanamycin,} 2.0 \mathrm{mmol} / 1$ glutamine, $1.0 \mathrm{mmol} / \mathrm{l}$ sodium pyruvate and $50 \mu \mathrm{mol} / 1 \beta$-mercaptoethanol. The cells were maintained at $37^{\circ} \mathrm{C}$ and in $5 \% \mathrm{CO}_{2}$.

For the measurement of cell doubling time, the INS-1 cells were harvested by trypsinization and seeded into normal 96-well dishes $\left(2.5 \times 10^{5} /\right.$ well $)$. The optical density at $490 \mathrm{~nm}$ was detected at the indicated times by the VersaMax microplate reader (Molecular Devices, Sunnyvale, CA, USA).

Toxicity assay. The INS-1 cells $\left(2.5 \times 10^{4} /\right.$ well) were seeded into 96-well plates. The medium was changed after $40-50 \%$ confluence was reached. The cells were incubated with fresh medium containing different concentrations of PMFs $(0,12.5$, $25,50,60,70,80$ and $90 \mu \mathrm{g} / \mathrm{ml})$ for $72 \mathrm{~h}$ and the medium was changed every $24 \mathrm{~h}$. The control cells were treated with DMSO for the same time. After $72 \mathrm{~h}$, cell viability was assessed using the MTT method as previously described (21). Briefly, the cells were pulsed with $20 \mu 1$ of a $5-\mathrm{mg} / \mathrm{ml}$ MTT stock in PBS and incubated for $4 \mathrm{~h}$, after which time $150 \mu \mathrm{l}$ of DMSO was added. The plates were then placed on a shaker for $10 \mathrm{~min}$ and absorption was read on a VICTOR 3 multilabel plate reader (Perkin-Elmer, Turku, Finland) using a test wavelength of $490 \mathrm{~nm}$. Test reagents (DMSO) alone were added to the medium to provide a blank.

Insulin secretion assay. The INS-1 cells $\left(2.5 \times 10^{4} /\right.$ well $)$ were seeded into 24-well plates. After cell confluence reached $60-70 \%$, the medium was removed and the cells were treated with Krebs-Ringer bicarbonate buffer (KRB; $129 \mathrm{mmol} / 1 \mathrm{NaCl}, 5 \mathrm{mmol} / 1 \mathrm{NaHCO}_{3}, 4.8 \mathrm{mmol} / \mathrm{l} \mathrm{KCl}$, $1.2 \mathrm{mmol} / 1 \mathrm{KH}_{2} \mathrm{PO}_{4}, 1.2 \mathrm{mmol} / 1 \mathrm{MgSO}_{4} \cdot 7 \mathrm{H}_{2} \mathrm{O}$ and
$2.5 \mathrm{mmol} / \mathrm{l} \mathrm{CaCl}_{2}$ ) without glucose for $60 \mathrm{~min}$ to ensure that the cells were in a non-glucose metabolic state. Subsequently, KRB was removed and the cells were incubated with fresh KRB containing different concentrations of glucose $(3,11$ and $20 \mathrm{mmol} / \mathrm{l})$ and PMFs $(12.5,25,37.5$ and $50 \mu \mathrm{g} / \mathrm{ml})$ for $60 \mathrm{~min}$. After the 60-min incubation, the supernatants were collected for insulin measurement by ELISA, according to the manufacturer's instructions.

RT-PCR. The cells were lysed with TRIzol and RNA was extracted with the RNeasy mini kit (Qiagen, Hilden, Germany), according to the manufacturer's instructions. The RNA samples were treated with DNase and used for RT-PCR according to the manufacturer's instructions. The sequences of the primers used were as follows: $\beta$-actin: sense, 5'-AGAAGGATTCCTATGTGGGCG-3' and antisense, 5'-CATGTCGTCCCAGTTGGTGAC-3'; insulin: sense, 5'-CAGCTCCACACTCCAGGTAC-3' and antisense, 5'-CTTTCGCTGGGCTCTGAAGG-3'; pancreatic and duodenal homeobox 1 (PDX1): sense, 5'-ATGAATAGTGAG GAGCAGTACTACG-3' and antisense, 5'-CCGGGGTTC CTGCGGTC-3'. For relative quantification, we calculated the $\mathrm{n}$-fold differential expression with the $\Delta \mathrm{Ct}$ method $(\mathrm{Ct}$, threshold cycle of PCR amplification at which the product is first detected by fluorescence), which compares the amount of target gene amplified normalized to the $\beta$-actin endogenous reference. The sizes of the amplified products were measured by electrophoresis on $1.5 \%$ agarose gels and visualized by ethidium bromide staining (22).

Statistical analysis. The results are expressed as the means \pm standard deviation. One-way analysis of variance (ANOVA) and the Student's t-test were performed using SPSS software for Windows, version 12.0, 2003 (SPSS Inc., Chicago, IL, USA). $\mathrm{P}<0.05$ was considered to indicate a statistically significant difference. All the assays were performed in triplicate. 
Table I. Toxicity of different concentrations of polymethoxylated flavones (PMFs) on INS-1 cells.

\begin{tabular}{llc}
\hline $\begin{array}{l}\text { Concentration of } \\
\text { PMFs }(\mu \mathrm{g} / \mathrm{ml})\end{array}$ & $\mathrm{OD}_{490}$ & Inhibition ratio (\%) \\
\hline 0 & 0.478 & - \\
12.5 & 0.468 & 2.1 \\
25 & 0.456 & 4.6 \\
50 & 0.47 & 1.6 \\
60 & 0.461 & 3.5 \\
70 & 0.432 & 9.6 \\
80 & $0.321^{\mathrm{a}}$ & 32.8 \\
90 & $0.33^{\mathrm{a}}$ & 30.9 \\
\hline
\end{tabular}

${ }^{\mathrm{a}} \mathrm{P}<0.05$, significant difference compared to the control group; OD, optical density.

\section{Results}

Characterization of PMFs. In this study, PMFs were extracted from dried tangerine peel with ethyl acetate at room temperature and the extract was analyzed by HPLC (Fig. 1). PMF crystals $(1.05 \mathrm{~g})$ were extracted from $1 \mathrm{~kg}$ dried tangerine peel and the content of PMFs was $83.9 \%$, according to the peak area regression method. These compounds were used for the subsequent experiments.

Determination of doubling time of INS-1 cells. To ensure that the INS-1 cells were in an optimal state for the subsequent experiments, the cell doubling time was determined using a test wavelength of $490 \mathrm{~nm}$. As shown in Fig. 2, the growth of the cells followed an exponential trend between 48 and $144 \mathrm{~h}$. After culture for $120 \mathrm{~h}$, the cell proliferation rate decreased. The confluence reached $70-80 \%$ after $6 \mathrm{~h}$ in culture and did not increase any further. These preliminary tests formed the basis for the subsequent experiments.

Cytotoxic activity of PMFs. To investigate the cytotoxic effect of PMFs on INS-1 cells, the cell viability under treatment with different concentrations of PMFs was measured with the MTT assay. The cells were incubated with different concentrations of PMFs for $72 \mathrm{~h}$. As shown in Table I, following a 72-h incubation, no cytotoxicity was observed in the $0-70 \mu \mathrm{g} / \mathrm{ml}$ concentration range compared to the DMSO-treated group $(\mathrm{P}>0.05)$. However, when INS-1 cells were treated with PMF concentrations of $\geq 80 \mu \mathrm{g} / \mathrm{ml}$, a cytotoxic effect was observed after $12 \mathrm{~h}$ of incubation. Morphological changes, such as cell shrinkage and condensation, were observed. After $24 \mathrm{~h}$ of incubation, there were more cells in suspension and the number of suspended cells increased at later times. Significant differences were observed $(\mathrm{P}<0.05)$.

PMFs exert no effect on insulin secretion by INS-1 cells. To achieve a preliminary understanding of the molecular mechanism of PMF function in diabetes, the INS-1 cells were treated with different concentrations of glucose, mimicking a hyperglycemic environment. The insulin secre-

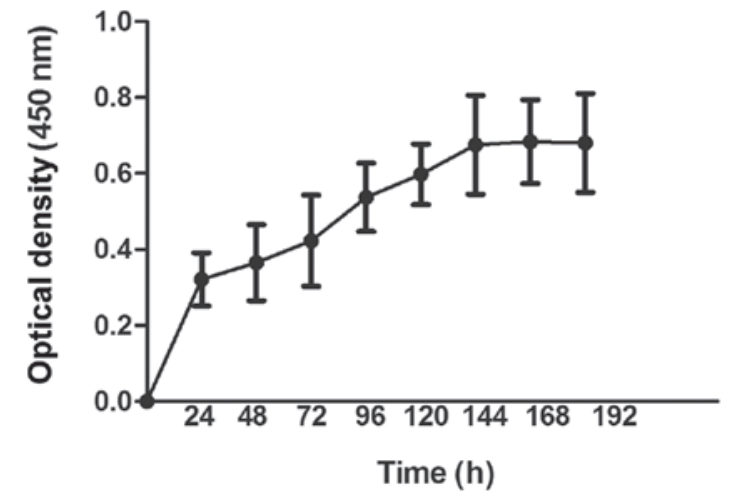

Figure 2. INS-1 cell doubling time measured with the MTT assay.

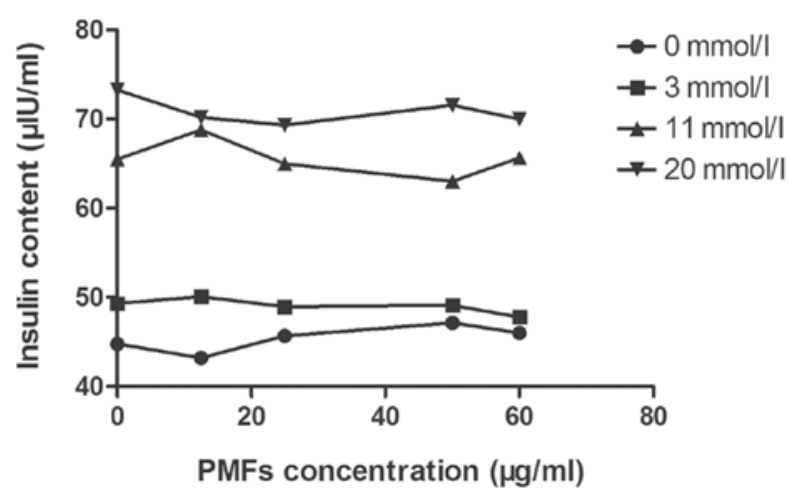

Figure 3. Insulin secretion by INS-1 cells treated with different concentrations of glucose and polymethoxylated flavones (PMFs).

tion by INS-1 cells treated with different concentrations of glucose and PMFs was assessed using ELISA. As shown in Fig. 3, following incubation with the same concentration of glucose and different concentrations of PMFs, no significant difference was observed among groups $(\mathrm{P}>0.05)$. At the same concentration of PMFs, no significant difference was observed in insulin secretion at different concentrations of glucose $(\mathrm{P}>0.05)$.

PMFs do not induce insulin or PDX1 mRNA expression. Subsequently, we investigated whether PMFs affect the expression of insulin mRNA using RT-PCR. The INS-1 cells were treated with $25 \mu \mathrm{g} / \mathrm{ml}$ PMFs and were collected at indicated times for RNA isolation and RT-PCR. As shown in Fig. 4A and $\mathrm{B}$, the incubation with PMFs exerted no significant effect on insulin mRNA expression in the INS-1 cells compared to that in the control cells $(\mathrm{P}>0.05)$.

We also analyzed the mRNA levels of PDX1, which is an insulin secretion-stimulating factor. Following incubation with $25 \mu \mathrm{g} / \mathrm{ml}$ PMFs for different time periods (Fig. 4C and D), the PDX1 mRNA levels were not found to be significantly altered compared to those in the control group $(\mathrm{P}>0.05)$.

\section{Discussion}

In the present study, PMFs were extracted from dried Pericarpium Citri Reticulatae and used to treat INS-1 cells. The 
A

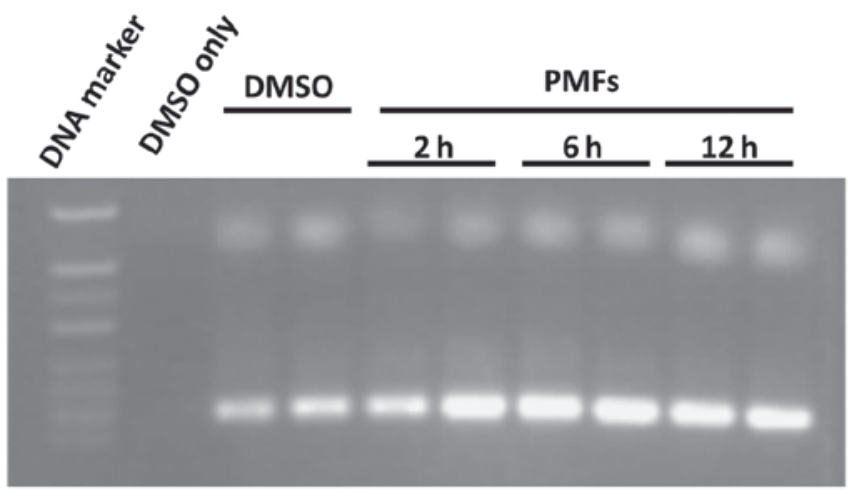

C

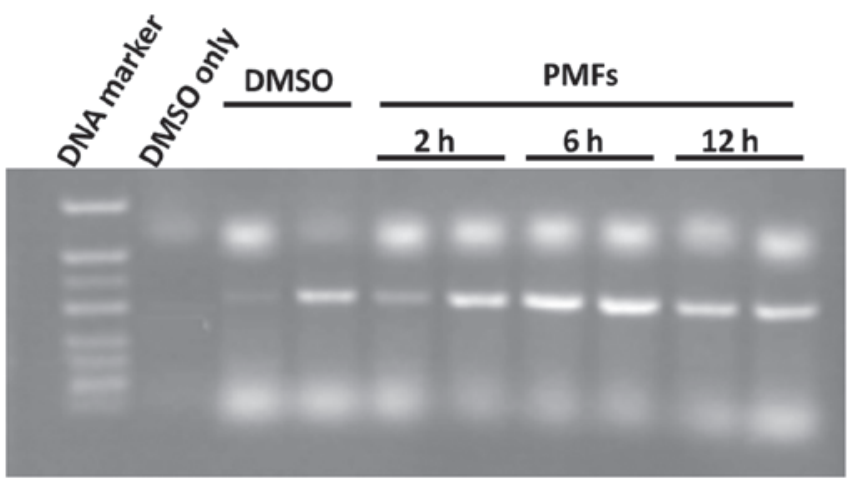

B

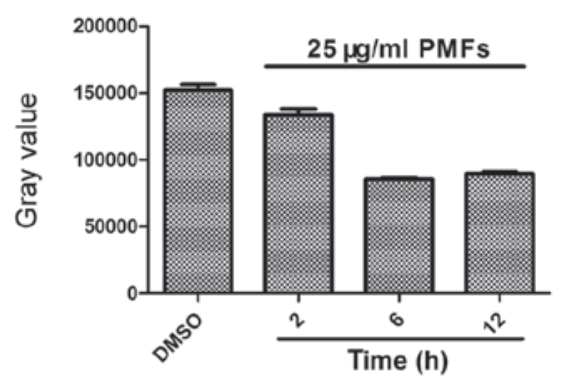

D

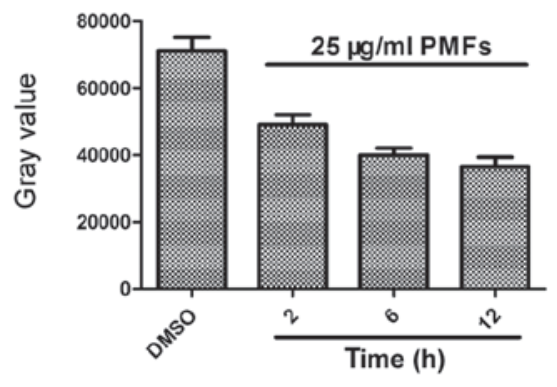

Figure 4. Insulin and pancreatic and duodenal homeobox 1 (PDX1) mRNA expression in INS-1 cells treated with polymethoxylated flavones (PMFs) and control cells. (A and C) INS-1 cells treated with PMFs and control cells were collected for reverse transcriptase-polymerase chain raction to determine the insulin and PDX1 mRNA levels; (B and D) gray values of insulin and PDX1 cDNA.

insulin mRNA and protein levels and the PDX1 mRNA levels were determined and PMFs were not shown to induce insulin secretion or mRNA expression. We also observed that the PDX1 levels were not significant altered with PMF treatment. To the best of our knowledge, this study is the first to provide evidence that the antidiabetic properties of PMFs are not mediated through the induction of insulin and PDX1 expression in pancreatic $\beta$-cells.

PMFs are the characteristic flavones of tangerine and are of particular interest due to their anticancer, anti-inflammatory, antioxidant, antimutagenic and antimicrobial properties $(1,11,23)$. The almost flat molecular structure and slightly polar nature enable PMFs to readily enter cells and perform their functions. Our results demonstrated no cytotoxic effect exerted by PMFs in the concentration range of $0-70 \mu \mathrm{g} / \mathrm{ml}$, suggesting that PMFs may be used as dietary supplements for the prevention and treatment of diabetes.

The secretion of insulin by pancreatic $\beta$-cells is characterized by two phases. In the first phase, pancreatic $\beta$-cells are stimulated by glucose or other inducers and the resulting increase in the ATP/ADP ratio closes the ATP-sensitive potassium KATP channel, causing plasma membrane depolarization, influx of $\mathrm{Ca}^{2+}$ and, finally, insulin secretion $(24,25)$. In another signaling pathway, neurotransmitters and hormones stimulate G-protein coupled receptors, regulating the level of intracellular secondary messengers, such as inositol triphosphate, diacylglycerol and $\mathrm{Ca}^{2+}$, which in turn regulate insulin secretion through protein kinases $\mathrm{A}$ and $\mathrm{C}$. These pathways regulate glucose and lipid metabolism in pancreatic $\beta$-cells by stimulating exocytosis and insulin secretion from these vesicles (26). During the second phase of insulin secretion, pancreatic $\beta$-cells increase insulin expression through specific signal transduction pathways. In this study, the effect of PMFs on the two phases of insulin secretion was investigated. To the best of our knowledge, our results were the first to demonstrate that PMFs do not induce insulin secretion through affecting the exocytosis of pancreatic cells, either directly or indirectly. In addition, PMFs were shown to exert no significant effect on the expression of PDX1, which is the main regulator of insulin expression. The antidiabetic properties of PMFs may lie with their potential effect on peripheral tissue cells, increasing their sensitivity to insulin. In addition, PMFs may also affect the glucose and lipid metabolism of liver and other tissues. The elucidation of the pathways through which PMFs exert their antidiabetic effects requires further investigation.

In conclusion, this study adds to our understanding of the antidiabetic properties of PMFs, which were found to be unrelated to insulin expression and secretion by pancreatic $\beta$-cells.

\section{Acknowledgements}

This study was supported by grants from the Research Project of Shaanxi Provincial Key Laboratory of Biotechnology (no. 11JS085), the Development Project of Science and Technology Research of Shaanxi Province (no. 2011K12-61) and the Natural Science Research Specialized Foundation of Department of Education of Shaanxi Province (no. 09JK754). We would like to thank Professor Dongmin Li for her technical assistance and supply of the INS-1 cells. 


\section{References}

1. Camarda L, Di Stefano V, Del Bosco SF and Schillaci D: Antiproliferative activity of Citrus juices and HPLC evaluation of their flavonoid composition. Fitoterapia 78: 426-429, 2007.

2. Nogata Y, Sakamoto K, Shiratsuchi H, Ishii T, Yano M and Ohta H: Flavonoid composition of fruit tissues of citrus species. Biosci Biotechnol Biochem 70: 178-192, 2006.

3. Tripoli E, Guardia ML, Giammanco S, Majo DD and Giammanco M: Citrus flavonoids: molecular structure, biological activity and nutritional properties: a review. Food Chem 104: 466-479, 2007

4. Murakami A, Nakamura Y, Ohto Y, et al: Suppressive effects of citrus fruits on free radical generation and nobiletin, an anti-nflammatory polymethoxyflavonoid. Biofactors 12: 187-192, 2000.

5. Lai CS, Li S, Chai CY, et al: Inhibitory effect of citrus 5-hydroxy$3,6,7,8,3^{\prime}, 4^{\prime}$-hexamethoxyflavone on 12 - $O$-tetradecanoylphorbol 13 -acetate-induced skin inflammation and tumor promotion in mice. Carcinogenesis 28: 2581-2588, 2007.

6. Murakami A, Nakamura Y, Torikai K, et al: Inhibitory effect of citrus nobiletin on phorbol ester-induced skin inflammation, oxidative stress, and tumor promotion in mice. Cancer Res 60: 5059-5066, 2000.

7. Tang MX, Ogawa K, Asamoto M, et al: Protective effects of citrus nobiletin and auraptene in transgenic rats developing adenocarcinoma of the prostate (TRAP) and human prostate carcinoma cells. Cancer Sci 98: 471-477, 2007.

8. Kurowska EM and Manthey JA: Hypolipidemic effects and absorption of citrus polymethoxylated flavones in hamsters with diet-induced hypercholesterolemia. J Agric Food Chem 52: 2879-2886, 2004.

9. Suzuki R, Kohno H, Murakami A, et al: Citrus nobiletin inhibits azoxymethane-induced large bowel carcinogenesis in rats. Biofactors 22: 111-114, 2004

10. Choi SY, Ko HC, Ko SY, et al: Correlation between flavonoid content and the NO production inhibitory activity of peel extracts from various citrus fruits. Biol Pharm Bull 30: 772-778, 2007.

11. Yoshimizu N, Otani Y, Saikawa Y, et al: Anti-tumour effects of nobiletin, a citrus flavonoid, on gastric cancer include: antiproliferative effects, induction of apoptosis and cell cycle deregulation. Aliment Pharmacol Ther 20: 95-101, 2004.

12. Li S, Sang S, Pan MH, et al: Anti-inflammatory property of the urinary metabolites of nobiletin in mouse. Bioorg Med Chem Lett 17: 5177-5181, 2007.

13. Chen KH, Weng MS and Lin JK: Tangeretin suppresses IL-1beta-induced cyclooxygenase (COX)-2 expression through inhibition of $\mathrm{p} 38$ MAPK, JNK, and AKT activation in human lung carcinoma cells. Biochem Pharmacol 73: 215-227, 2007.
14. Pan MH, Chen WJ, Lin-Shiau SY, Ho CT and Lin JK: Tangeretin induces cell-cycle G1 arrest through inhibiting cyclin-dependent kinases 2 and 4 activities as well as elevating Cdk inhibitors p21 and p27 in human colorectal carcinoma cells. Carcinogenesis 23: $1677-1684,2002$

15. Li S, Lo CY and Ho CT: Hydroxylated polymethoxyflavones and methylated flavonoids in sweet orange (Citrus sinensis) peel. J Agric Food Chem 54: 4176-4185, 2006.

16. Raman G, Jayaprakasha G, Cho M, Brodbelt J and Patil BS: Rapid adsorptive separation of citrus polymethoxylated flavones in non-aqueous conditions. Sep Purif Technol 45: 147-152, 2005.

17. Choi SY, Hwang JH, Ko HC, Park JG and Kim SJ: Nobiletin from citrus fruit peel inhibits the DNA-binding activity of $\mathrm{NF}-\kappa \mathrm{B}$ and ROS production in LPS-activated RAW 264.7 cells. J Ethnopharmacol 113: 149-155, 2007.

18. Hertog MGL, Hollman PCH and Van de Putte B: Content of potentially anticarcinogenic flavonoids of tea infusions, wines, and fruit juices. J Agric Food Chem 41: 1242-1246, 1993.

19. Lee YH, Charles AL, Kung HF, Ho CT and Huang TC: Extraction of nobiletin and tangeretin from Citrus depressa Hayata by supercritical carbon dioxide with ethanol as modifier. Industrial Crops and Products 31: 59-64, 2010.

20. Senevirathne M, Jeon YJ, Ha JH and Kim SH: Effective drying of citrus by-product by high speed drying: A novel drying technique and their antioxidant activity. J Food Eng 92: 157-163, 2009.

21. Kim H, Moon JY, Mosaddik A and Cho SK: Induction of apoptosis in human cervical carcinoma HeLa cells by polymethoxylated flavone-rich Citrus grandis Osbeck (Dangyuja) leaf extract. Food Chem Toxicol 48: 2435-2442,

22. Jiang L, Wei X, Yi D, et al: Synergistic effects of cyclic strain and Th1-like cytokines on tenascin-c production by rheumatic aortic valve interstitial cells. Clin Exp Immunol 155: 216-223, 2009.

23. Yi ZB, Yu Y, Liang YZ and Zeng B: In vitro antioxidant and antimicrobial activities of the extract of Pericarpium Citri Reticulatae of a new Citrus cultivar and its main flavonoids. LWT-Food Sci Technol 41: 597-603, 2008.

24. Ashcroft FM and Gribble FM: Tissue-specific effects of sulfonylureas: lessons from studies of cloned KATP channels. J Diabetes Complications 14: 192-196, 2000.

25. Matschinsky F, Glaser B and Magnuson M: Pancreatic beta-cell glucokinase: closing the gap between theoretical concepts and experimental realities. Diabetes 47: 307-315, 1998.

26. Bratanova-Tochkova TK, Cheng H, Daniel S, et al: Triggering and augmentation mechanisms, granule pools and biphasic insulin secretion. Diabetes 51: S83-S90, 2002. 